\title{
3-Amino-1,2,4-triazole Limits the Oxidative Damage in UVA-Irradiated Dysplastic Keratinocytes
}

\author{
Marina Tamara Nechifor ${ }^{1}$ and Diana Dinu ${ }^{2}$ \\ ${ }^{1}$ Department of Anatomy, Physiology and Biophysics, University of Bucharest, 91-95 Splaiul Independentei, \\ 050095 Bucharest, Romania \\ ${ }^{2}$ Department of Biochemistry and Molecular Biology, University of Bucharest, 91-95 Splaiul Independentei, 050095 Bucharest, Romania
}

Correspondence should be addressed to Diana Dinu; diana_dinu2006@yahoo.com

Received 9 July 2017; Revised 28 October 2017; Accepted 23 November 2017; Published 13 December 2017

Academic Editor: Michele Rechia Fighera

Copyright (c) 2017 Marina Tamara Nechifor and Diana Dinu. This is an open access article distributed under the Creative Commons Attribution License, which permits unrestricted use, distribution, and reproduction in any medium, provided the original work is properly cited.

\begin{abstract}
Reactive oxygen species (ROS) generated by UVA irradiation affect the keratinocyte cell membrane, DNA, and proteins and may cause serious injury to the skin. Treating human dysplastic keratinocytes (DOK) with 3-amino-1,2,4-triazole (AMT), a common catalase inhibitor, induced a compensatory mechanism for the hydrogen peroxide detoxification, which included a rise in glutathione peroxidase and glutathione reductase activities. Here, we examined a possible role of AMT in protecting a human DOK cell line against UVA-induced damage. In DOK cells exposed to UVA irradiation, we observed a substantial decrease in antioxidant enzymatic activities, such as catalase, glutathione peroxidase, glutathione reductase, and glutathione-S-transferase and an increase in lipid peroxidation and protein oxidation levels. Treating DOK cells with AMT prior to UVA exposure enhanced the activities of glutathione peroxidase, glutathione reductase, and glutathione-S-transferase, relative to nontreated cells. The enhanced antioxidant activities were correlated with decreased protein oxidation levels. Based on these results, we suggest that AMT may protect dysplastic keratinocytes against the harmful effects of UVA radiation.
\end{abstract}

\section{Introduction}

Exposure of human skin to solar light may lead to shortand long-term cutaneous photobiological effects, such as inflammatory skin disorders, premature skin aging, and skin cancer [1, 2]. Ultraviolet light A (UVA, 320-400 nm) accounts for approximately $90 \%$ of the sunlight UV waveband that reaches the Earth's surface; thus, its contribution to the harmful effects must be carefully considered. UVA radiation is penetrative and reaches targets well below the skin surface, acting on the basal layer of the epidermis, where proliferating keratinocytes reside [3]. Previous studies have demonstrated that UVA may cause substantial oxidative stress in skin cells $[4,5]$. After its absorption by endogenous chromophores, UVA radiation may lead to the formation of reactive oxygen species (ROS), which in turn cause lipid peroxidation, protein oxidation, and DNA damage [6,7]. There are many cellular chromophores acting as photosensitizers for UVA radiation, including flavins, melanin, free porphyrins, and hemecontaining proteins such as cytochromes, peroxidases, and catalase [7]. When ROS formation exceeds a cell's biological defense capacity, oxidative stress occurs. Therefore, cellular antioxidant mechanisms in skin represent an important line of protection against UVA exposure. Among these defense mechanisms, skin cells rely on antioxidant enzymes, such as superoxide dismutase (SOD), catalase (CAT), glutathione peroxidase (GPX), peroxiredoxins (PRDX), and glutathioneS-transferase (GST) $[8,9]$. Each of these enzymes has specific roles in preventing oxidative damage and all must be functional for optimal antioxidant protection, although some overlap exists. For instance, both CAT and GPX act on reducing hydrogen peroxide levels, and the exact contribution of CAT and GPX in decomposition of hydrogen peroxide produced in human cell remains subject to debate $[10,11]$. One approach to elucidate the physiological function of each antioxidant enzyme during oxidative stress uses specific inhibitors. Specifically, 3-amino-1,2,4-triazole (AMT) is an inhibitor widely used for its controlled effects on catalase activity [12]. With this approach, several studies reported 
changes in oxidative stress markers and antioxidant defenses after AMT treatment in various animal models $[13,14]$ and in cell culture $[15,16]$. Some of these studies reported compensatory responses to AMT-induced catalase depletion [17].

In the present study, we examined how AMT inhibition of CAT affected the activities of GPX, GR, and GST, and the oxidative damage of lipids and proteins in UVA-exposed dysplastic keratinocytes. Our results are first to show that AMT treatment of keratinocytes prior to UVA irradiation increased the activities of GPX, GR, and GST and limited the levels of protein carboxylation. Based on these results, we propose that AMT activates a compensatory enzymatic mechanism against UVA-induced oxidative stress in keratinocytes.

\section{Materials and Methods}

2.1. Cell Culture and Treatment. Human Caucasian dysplastic oral keratinocytes (DOK, ECACC number 94122104) were from Sigma-Aldrich (St. Louis, MO, USA). Cells were cultured at $37^{\circ} \mathrm{C}$ under a $5 \% \mathrm{CO}_{2}$ humidified atmosphere in Dulbecco Modified Eagle's Medium (DMEM) supplemented with Ham F12 (3:1), 10\% fetal bovine serum, $2 \mathrm{mM} \mathrm{L-}$ glutamine, and antibiotic antimycotic solution. Cells were seeded at $10^{4}$ cells $/ \mathrm{cm}^{2}$ in $60 \mathrm{~mm}$ plastic Petri dishes and grown to $80 \%$ confluence. Prior to irradiation, the culture medium was removed. Cells were washed twice with $2 \mathrm{~mL}$ phosphate-buffered saline (PBS), left in $2 \mathrm{~mL} P B S$, and irradiated from the top at a distance of $10 \mathrm{~cm}$. For irradiation, we used a $365 \mathrm{~nm}$ UV lamp (model VL-340 BLB, Vilber Lourmat, France) at a light intensity of $381 \mu \mathrm{W} / \mathrm{cm}^{2}$. Irradiation was performed for $1 \mathrm{~h}$, which resulted in accumulated doses of $18.7 \mathrm{~J} / \mathrm{cm}^{2}$, as measured [18] with a LaserStar Power Meter, provided with a 3A-P photodetector (Ophir Optronics Solutions Ltd., Jerusalem, Israel). To avoid thermal stimulation, UVA exposure was done in a ventilated laminar flow hood (Safeflow 1.8, Bioair, Siziano, Italy). Control cells were similarly handled but were shielded from UVA with an aluminum foil sheet. For preliminary investigation of the effect on catalase inhibition, cells were treated with several AMT concentrations, between 0.01 and $2 \mathrm{mM}$. To investigate the cumulative effect of AMT and UVA irradiation on markers of oxidative stress and the activities of antioxidant enzymes, cells were treated with $1.5 \mathrm{mM}$ of AMT and then UVA irradiated for $1 \mathrm{~h}$.

2.2. Cell Viability. Cell viability was evaluated using the neutral red technique [19]. From a $50 \mathrm{mg} / \mathrm{l}$ solution of neutral red (in culture medium), $3 \mathrm{~mL}$ was added to each dish. Cells were reincubated for $3 \mathrm{~h}$ at $37^{\circ} \mathrm{C}$, resulting in the uptake of the vital dye into viable cells. The dye medium was removed and the cells were washed rapidly with $4 \%$ formaldehyde$1 \% \mathrm{CaCl}_{2}$ to remove unincorporated dye. Neutral red was extracted into $3 \mathrm{~mL}$ of a $1 \%$ acetic acid-50\% ethanol mixture. After $20 \mathrm{~min}$, the absorbance was measured at $540 \mathrm{~nm}$. The absorbance corresponding to the wells with control cells was set as the $100 \%$ viability value.

2.3. Intracellular Hydrogen Peroxide. Intracellular levels of hydrogen peroxide $\left(\mathrm{H}_{2} \mathrm{O}_{2}\right)$ were analyzed using dihydrorhodamine 123 (DHR) as described by Huang et al. [20]. DHR, a nonfluorescent substance, can passively diffuse across membranes and in the presence of $\mathrm{H}_{2} \mathrm{O}_{2}$ is irreversibly oxidized to rhodamine 123, a green fluorescent compound. Confluent keratinocytes treated with DHR $(10 \mu \mathrm{g} / \mathrm{mL})$ in DMEM for 30 minutes were collected by scraping and centrifugation. Cell pellets were resuspended in $1 \mathrm{~mL}$ PBS and then analyzed on a flow cytometer (Beckman Coulter, Inc., CA, USA) at excitation and emission wavelengths of $488 \mathrm{~nm}$ and $525 \mathrm{~nm}$, respectively. The fluorescence signal from 10,000 cells was collected to calculate the mean fluorescence intensity of a single cell.

2.4. Protein Oxidation. Protein oxidation was evaluated by measuring carbonyl derivatives, the most common products of the covalent modification with the OxiSelect ${ }^{\mathrm{TM}}$ Protein Carbonyl ELISA Kit (San Diego, CA, USA). The protein carbonyls present in the sample or standard are derivatized to dinitrophenyl (DNP) hydrazone and probed with an anti-DNP antibody, followed by horseradish peroxidase (HRP) conjugated secondary antibody. The protein carbonyl content in the unknown sample is determined by comparing with a standard curve that is prepared from known reduced/oxidized bovine serum albumin (BSA) standards. The results were expressed as nanomoles of protein carbonyl per mg protein (nmole/mg).

2.5. Lipid Peroxidation. The level of lipid peroxidation was measured via the 2-thiobarbituric acid (TBA) color reaction for malondialdehyde (MDA), an end product of lipid peroxidation, by the modified method of Portolés et al. [21]. Cultured DOK cells were homogenized in $1 \mathrm{~mL}$ of $0.1 \mathrm{M}$ saline phosphate buffer and sonicated on ice, at $40 \mathrm{~V}, 3$ times for 30 seconds each. Then, $0.375 \mathrm{~mL}$ of $40 \%(\mathrm{w} / \mathrm{v})$ trichloroacetic acid (TCA) and $0.2 \mathrm{~mL}$ of $0.1 \mathrm{M}$ of TBA were added to lysates. The samples were incubated at $90^{\circ} \mathrm{C}$ for $30 \mathrm{~min}$ and a volume of $0.625 \mathrm{~mL}$ distilled water was added. Cells were centrifuged at $5000 \mathrm{rpm}$ for 10 minutes. The level of lipid peroxidation in the supernatants was determined by the absorbance at $532 \mathrm{~nm}$, using a MDA solution, freshly made by the hydrolysis of 1,1,3,3-tetramethoxypropane, as a standard. The results were expressed as nmoles of MDA per $\mathrm{mL}$.

2.6. Enzymes Activity Assays. Harvested cells were homogenized with $50 \mathrm{mM}$ potassium phosphate buffer ( $\mathrm{pH}$ 7.5), $0.2 \%$ Triton X-100, and $0.5 \mathrm{mM}$ phenylmethylsulfonyl fluoride (PMSF) and sonicated three times for 30 seconds on ice. Total cell lysates were centrifuged at $3000 \mathrm{rpm}, 4^{\circ} \mathrm{C}$ for 15 minutes, and aliquots of the supernatant were used for subsequent enzymatic assays.

The CAT activity was assayed by monitoring the disappearance of $\mathrm{H}_{2} \mathrm{O}_{2}$ at $240 \mathrm{~nm}$, according to the method of Aebi [22]. The CAT activity was calculated in terms of $\mathrm{U} / \mathrm{mg}$ protein, where one unit (U) is the amount of enzyme that catalyzed the conversion of one $\mu$ mole $\mathrm{H}_{2} \mathrm{O}_{2}$ in a minute under standard condition of temperature, optimal $\mathrm{pH}$, and optimal substrate concentration. Selenium-dependent GPX activity was measured by an indirect method [23], using tert-butyl hydroperoxide as substrate. This assay is based on the transformation of glutathione (GSH) to oxidized 
glutathione (GSSG) catalyzed by GPX, which is then coupled to the recycling of GSSG back to GSH utilizing glutathione reductase (GR) and reduced nicotinamide adenine dinucleotide phosphate (NADPH). The conversion of NADPH to $\mathrm{NADP}^{+}$was followed by recording the changes in absorbance intensity at $340 \mathrm{~nm}$, and the concentration of NADPH was calculated using a molar extinction coefficient of $6.22 \times$ $10^{3} \mathrm{M}^{-1} \mathrm{~cm}^{-1}$. One unit of activity was defined as the amount of enzyme that catalyzes the conversation of one $\mu$ mole NADPH per minute, under standard condition.

The GR activity was measured according to the method of Goldberg and Spooner [24], in 0.1 M phosphate buffer, $\mathrm{pH}$ 7.4 with $0.66 \mathrm{mM}$ GSSG, and $0.1 \mathrm{mM}$ NADPH by recording the decrease of absorbance at $340 \mathrm{~nm}$. The activity of this enzyme was expressed as $\mathrm{mU} / \mathrm{mg}$; one unit of GR activity has been calculated as one $\mu$ mole of NADPH consumed per minute under standard condition. The concentration of NADPH transformed under GR action was calculated using a molar extinction coefficient of $6.22 \times 10^{3} \mathrm{M}^{-1} \mathrm{~cm}^{-1}$.

The GST (EC 2.5.1.18) activity was assayed spectrophotometrically, at $340 \mathrm{~nm}$ by measuring the rate of 1-chloro-2,4dinitrobenzene (CDNB) conjugation with GSH, according to the method of Habig et al. [25], and calculated as $\mathrm{mU} / \mathrm{mg}$. One unit of GST activity was defined as the amount of enzyme that catalyzed the transformation of one $\mu$ mole of CDNB in conjugated product per minute. The extinction coefficient $9.6 \mathrm{mM}^{-1} \mathrm{~cm}^{-1}$ of was used for the calculation of CDNB concentration.

All enzymatic activities, calculated as specific activities (units/mg protein), were expressed as \% relative to controls.

2.7. Protein Concentration. The protein concentration, expressed as $\mathrm{mg} / \mathrm{mL}$, was determined by the method of Bradford [26], using bovine serum albumin as a standard.

2.8. Western Blotting. Samples of $10 \mu \mathrm{g}$ protein were derivatized with 2,4-dinitrophenylhydrazine (DNPH) following the reagents and conditions described by Thiele et al. [27] and separated by $10 \%$ sodium dodecyl sulfate polyacrylamide gel electrophoresis (SDS-PAGE). Separated proteins were electrotransferred onto polyvinylidene difluoride (PVDF) membrane. The membranes were blocked in 5\% blocking reagent in Tris buffered saline Tween (TBS-T) and incubated with a rabbit anti-dinitrophenylhydrazone antibody (SigmaAldrich, St. Louis, USA) in $1 \%$ TBS-T $(1: 150)$ for $18 \mathrm{~h}$ at $4^{\circ} \mathrm{C}$. Primary antibody binding was detected by incubation with a peroxidase-conjugated secondary antibody $(1: 300)$ (Sigma-Aldrich, St. Louis, USA) for $1 \mathrm{~h}$ at room temperature. The membranes were then treated with the chemiluminescent substrate Luminata Forte (Merck Millipore, UK). The oxidized protein bands were detected with the Luminescent Image Analyzer (FujiFilm, UK) and quantified with GelQuant.NET software. Loading control was made using the same amount of samples separated by SDS-PAGE in the same conditions and stained with sensitive Coomassie Blue stain.

2.9. Statistical Analysis. Five replicates were performed to calculate the averages and standard deviations of the experimental data, while duplication was used to test for reproducibility of each applied assays.

Statistical analyses were carried out using analysis of variance (ANOVA). The post hoc comparisons between the means of the groups were done by Duncan's Multiple Range Test (DMRT). Data were analyzed using the SPSS ${ }^{\mathrm{R}}$ for Windows computer program (Version 10.0). All data were expressed as means \pm SD from analysis of duplicate of five independent experiments. The differences were considered significant at $p<0.05$.

\section{Results}

3.1. Dose and Time Effect of AMT on Catalase. We incubated keratinocytes for $1 \mathrm{~h}$ with several AMT concentrations $(0.01-2 \mathrm{mM})$ and measured a progressive decrease of CAT activity (Figure 1(a)). This effect was concentrationdependent with maximum inhibition observed at $1.5 \mathrm{mM}$ AMT (Figure 1). The time course of CAT inactivation was observed during $24 \mathrm{~h}$. The CAT activities had a deep decline up to an $\mathrm{h}$ of incubation. Thus, after $1 \mathrm{~h}$ of incubation with $1.5 \mathrm{mM}$ AMT, the CAT activity was significantly reduced (approximatively 5-fold) compared to untreated cells (Figure 1(b)). This low level in CAT activity persisted up to $24 \mathrm{~h}$ of screening (Figure 1(b)). According to these results, the final chosen condition for the following experiments was $1.5 \mathrm{mM}$ AMT for $1 \mathrm{~h}$ treatment.

3.2. Catalase Inhibition Induced Reactive Oxygen Species Generation in DOK Cells. Next we investigated the effect of AMT on ROS production and oxidative damage to lipids and proteins in DOK cells. As shown in Table 1, flow cytometric analysis showed that the mean fluorescence, that is, $\mathrm{H}_{2} \mathrm{O}_{2}$ production, was 2.2-fold increase in AMT-treated cells (Table 1 ). The treatment of DOK cells with $1 \mathrm{mM}$ AMT resulted in an approximately 1.5-fold increase in lipid peroxidation content, while the amount of oxidatively damaged proteins showed only a minor increase (Table 1). The effect of AMT on the enzymes of the glutathione redox cycle was also investigated. The activity of GPX was upregulated by $150 \%$, GR was increased by $68 \%$, while GST activity remained almost unmodified after AMT treatment (Table 1).

3.3. Cell Viability. The incubation of DOK cells with $0.1,0.25$, 0.5 , and $0.75 \mathrm{mM}$ AMT for $1 \mathrm{~h}$ had no significant effect on viability. The decrease in cell viability induced by $1 \mathrm{mM}$ AMT exposure was $14 \%$ from control. After the treatment of DOC cells with the highest of AMP concentrations of 1.5 and $2 \mathrm{mM}$, the viability decreased by $25 \%$ and by $31 \%$, respectively, but statistical analysis showed no significant difference between them (Figure 2(a)).

To examine whether UVA, AMT, or AMT + UVA can lead to keratinocyte death, we performed cell viability assays. As shown in Figure 2(b), we noticed an approximate 25\% decrease in cell viability after UVA irradiation and a similar decrease after AMT treatment, while in AMT-treated UVAirradiated cells the loss in cell viability was about $29 \%$ from the control value. 
TABLE 1: The effect of $1.5 \mathrm{mM}$ AMT on intracellular $\mathrm{H}_{2} \mathrm{O}_{2}$ level, lipid peroxidation, protein oxidation, and antioxidant enzymes in DOK cells. ${ }^{*} p<0.05$ versus control.

\begin{tabular}{|c|c|c|c|c|c|c|}
\hline & $\begin{array}{c}\text { Intracellular } \mathrm{H}_{2} \mathrm{O}_{2} \text { level } \\
\text { (main fluorescence) }\end{array}$ & $\begin{array}{l}\text { Lipid peroxidation } \\
\text { (nmoles } / \mathrm{mL})\end{array}$ & $\begin{array}{l}\text { Protein oxidation } \\
\text { (nmoles/mg) }\end{array}$ & $\begin{array}{c}\text { GPX } \\
(\mathrm{U} / \mathrm{mg})\end{array}$ & $\begin{array}{c}\text { GST } \\
(\mathrm{U} / \mathrm{mg})\end{array}$ & $\begin{array}{c}\mathrm{GR} \\
(\mathrm{U} / \mathrm{mg})\end{array}$ \\
\hline Control & 8.52 & 0.136 & 3.61 & 9.71 & 120.66 & 5.39 \\
\hline AMT & $18.92^{*}$ & $0.206^{*}$ & $4.81^{*}$ & $24.3^{*}$ & 111.72 & $9.16^{*}$ \\
\hline
\end{tabular}

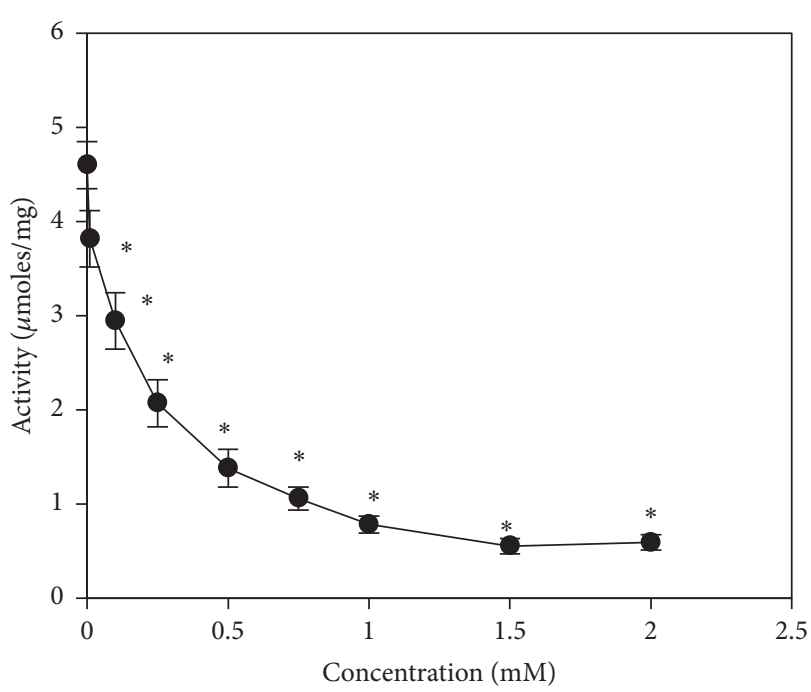

(a)

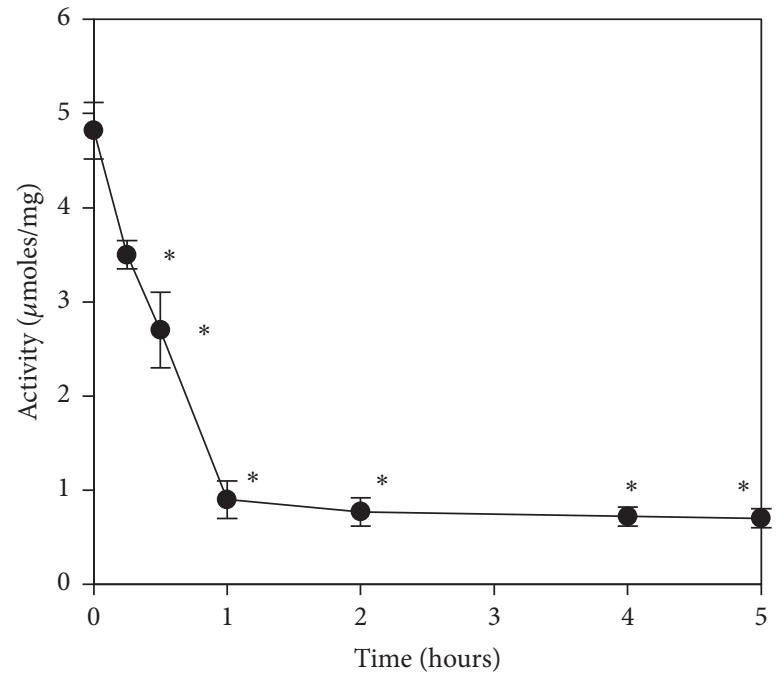

(b)

FIGURE 1: Dose- and time-dependent inhibition of CAT activity in keratinocytes treated with AMT. (a) Effect of several concentration of AMT; (b) effect of incubation time of DOK cells in culture media supplemented with $1.5 \mathrm{mM}$ AMT. The values are calculated as means of five experiments performed in duplicate \pm SD. $*$ indicates significant difference relative to controls $(p<0.05)$.

3.4. The Antioxidant Enzymes. Exposure of DOK cells to UVA, AMT, or AMT + UVA produced a significant decrease in CAT activities (Figure 3(a)). CAT activity decreased by $61.6 \%$ and by $80.3 \%$, after UVA exposure and AMT treatment, respectively. The most dramatic loss in CAT activity was recorded in AMT-treated UVA-irradiated cells, where the residual CAT activity represented only $8.9 \%$ of control (Figure 3(a)).

For the other antioxidant enzymes, GPX and GR, we observed distinct responses relative to CAT (Figures 3(b) and $3(\mathrm{c})$ ). Thus, we recorded a decrease in both enzyme activities after UVA irradiation, whereas AMT-treated cells had increased levels of these antioxidant activities. The incubation of DOK cells with AMT before UVA exposure not only prevented the depletion of GPX by UVA exposure but also enhanced the level of this enzyme by $50 \%$ compared to control cells. The treatment with AMT prior to irradiation also induced $18 \%$ increase in GR activity in UVA-irradiated cells. Regarding GST, the results revealed that the inhibition of GST by UVA irradiation was also prevented, if DOK cells were incubated with AMT prior UVA exposure, and the activity level remains similar to that recorded for the nonirradiated cells (Figure 3(d)).

3.5. Lipid Peroxidation and Protein Oxidation. Lipid peroxidation levels, expressed as MDA, were significantly increased in UVA, AMT, and AMT + UVA treated cells, relative to control (Figure 4(a)). The most significant increase of $70 \%$ was recorded after UVA irradiation, but this high level was not significantly reduced through the treatment of keratinocytes with AMP prior to UVA exposure (Figure 4(a)). Following UVA exposure, a significant increase in protein oxidation occurred, as evident from the darker and/or new protein bands compared to nonirradiated cells, while protein carbonylation levels in AMT-treated cells were less affected (Figure 4(b)). The densitometry of the total oxidized proteins suggested a great increase in UVA-irradiated DOC cells, while the treatment of keratinocytes with AMT before irradiation significantly decreased the oxidative changes of proteins induced by UVA (Figure 4(c)).

\section{Discussions}

AMT is widely used to inhibit CAT activity and to investigate the physiological function of this antioxidant enzyme [12]. The removal of excess $\mathrm{H}_{2} \mathrm{O}_{2}$, which may result as a consequence of CAT inactivation, is very important to protect cellular components from oxidative damage.

At AMT concentrations between 0.1 and $1 \mathrm{mM}$ a sharp reduction in CAT activity was seen in the preliminary data. CAT activity decreased by more than $80 \%$ in DOK cells after $1.5 \mathrm{mM}$ AMT administration and remained at this level for 


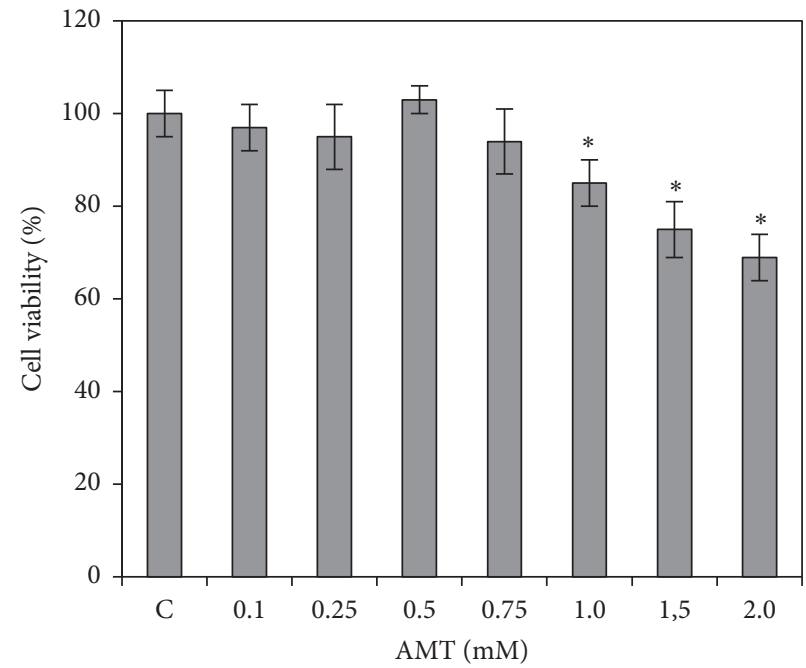

(a)

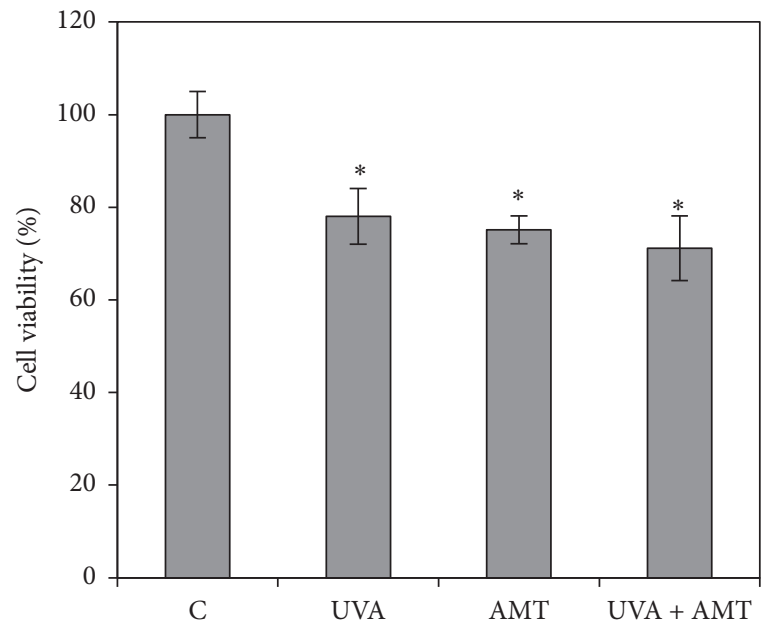

(b)

FIGURE 2: The viability of DOK cells exposure to AMT, at different concentrations (a), and the viability after UVA irradiation, AMT treatment, and the combined action of AMT treatment and UVA irradiation (b). The values are means \pm SD from analysis of duplicate of five independent experiments and expressed as \% from controls; ${ }^{*}$ significantly different from controls $(p<0.05)$.

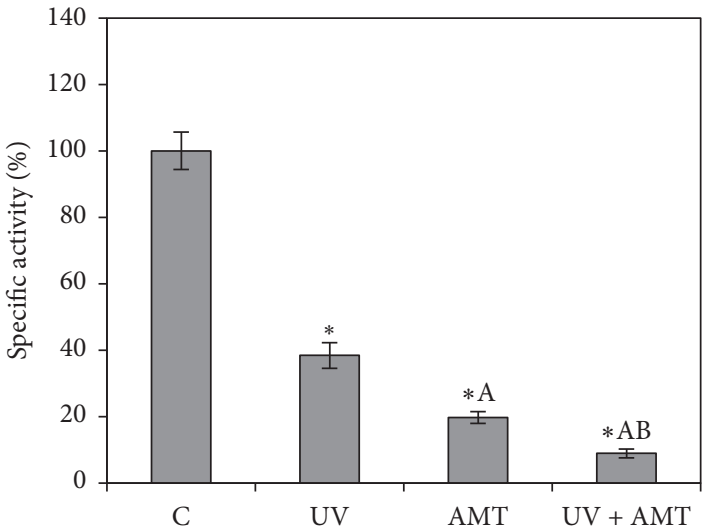

(a)

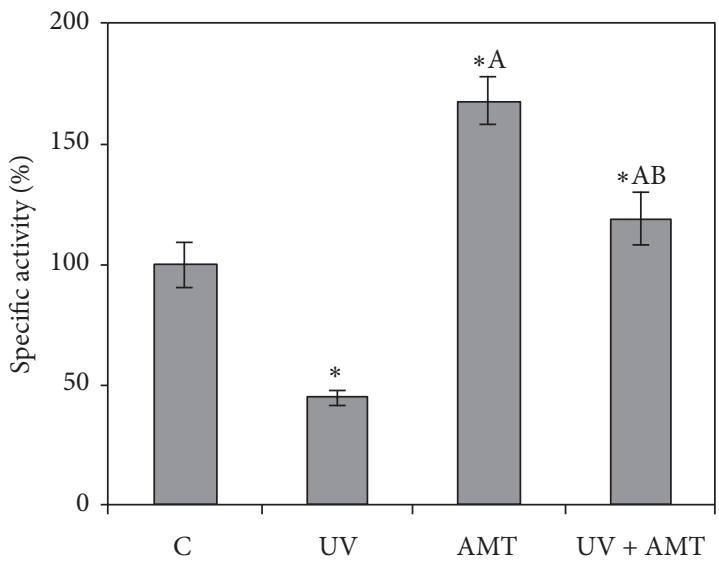

(c)

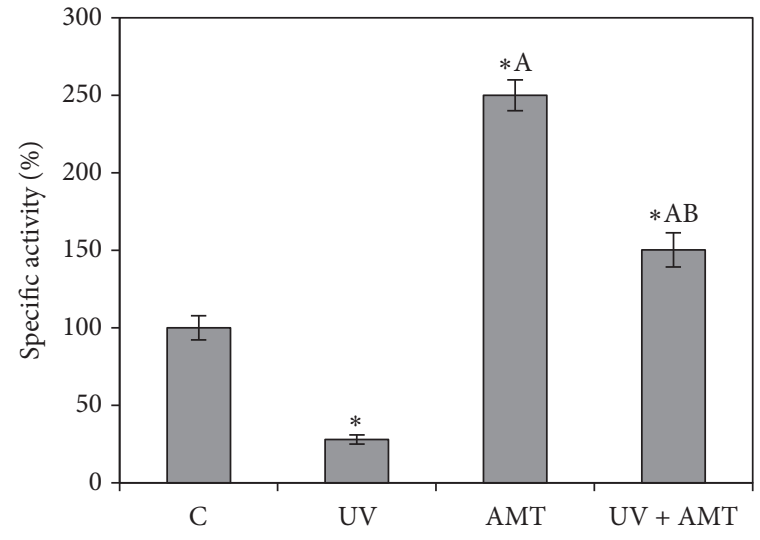

(b)

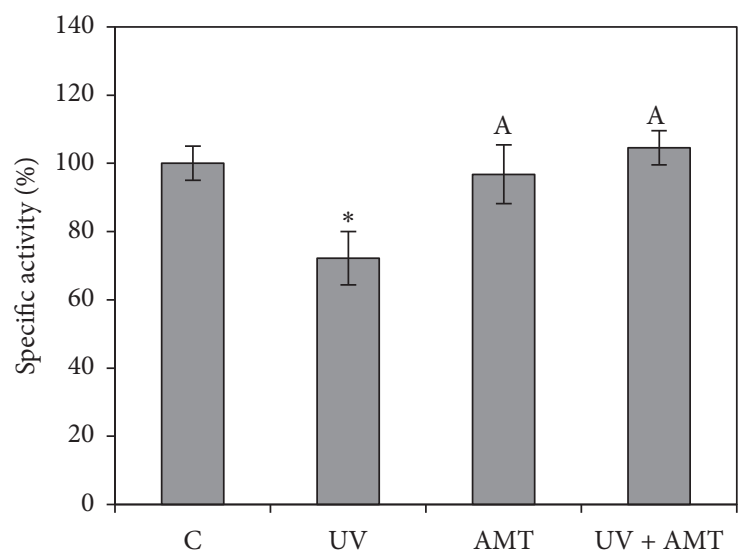

(d)

FIGURE 3: The effect of UVA exposure, AMT treatment, and concurrent AMT treatment and UVA exposure on antioxidant activities in DOK cells: CAT (a), GPX (b), GR (c), and GST (d). The values are calculated as means of five experiments performed in duplicate and expressed as \% from controls; ${ }^{*}$ significantly different from controls $(p<0.05)$; ${ }^{\text {A }}$ significantly different from UVA exposure $(p<0.05)$; ${ }^{B}$ significantly different from AMT treatment $(p<0.05)$. 


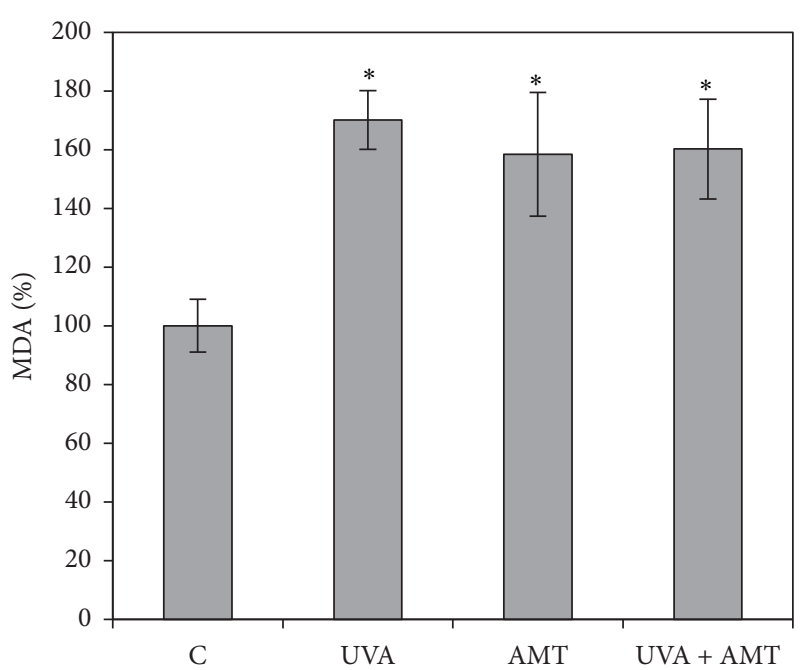

(a)
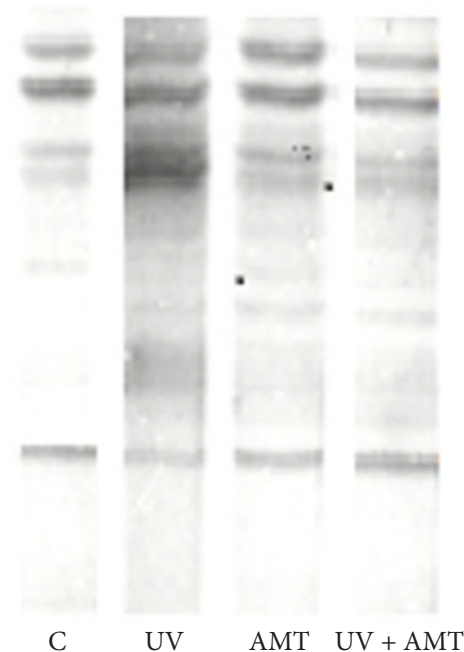

(b)

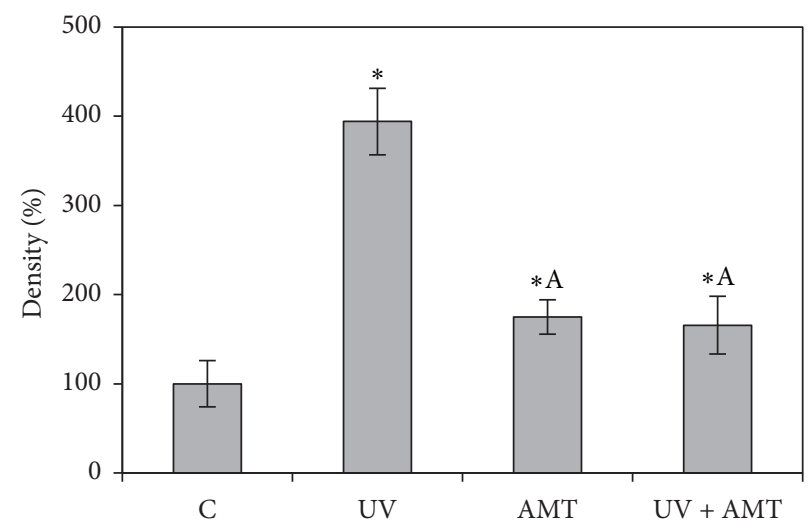

(c)

FIGURE 4: The effect of UVA exposure, AMT treatment, and concurrent AMT treatment and UVA exposure on lipid peroxidation (a) and on protein oxidation ((b), (c)) in DOK cells. (a) Values of MDA are means \pm SD from analysis of duplicate of five independent cultures and are expressed as \% from controls; (b) oxidized proteins detected by Western blot analysis: (c) the densitometry results for the level of oxidation of proteins were normalized to controls. The data are presented as means of three independent experiments \pm SD; ${ }^{*}$ significantly different from controls $(p<0.05)$; ${ }^{\text {A }}$ significantly different from UVA exposure $(p<0.05)$.

higher concentrations of AMT. In addition, the decrease in DOK cells viability at this AMT concentration was moderate. Using these preliminary data, we chose treatment with AMT at a concentration of $1.5 \mathrm{mM}$ as the design for the following experiments. In our experiments, we observed that depletion of CAT activity by AMT produced moderate oxidative stress in DOK cells. Specifically, the decrease of CAT activity by more 5-fold was accompanied by an increase of hydrogen peroxide level by only 2.2 -fold. These data suggest the involvement of alternative mechanisms for detoxifying $\mathrm{H}_{2} \mathrm{O}_{2}$. Keratinocytes possess cellular defense systems, which, under normal metabolic conditions, regulate the level of ROS and protect against their deleterious effects. One of these defense systems includes antioxidant enzymes, such as CAT, GPX, GST, and GR [28]. CAT inactivation by AMT in keratinocytes was accompanied by the enhancement in GPX activity. The GPX enzyme works in tandem with CAT to remove hydrogen peroxide: CAT converts the hydrogen peroxide into molecular oxygen and water, while GPX uses reduced glutathione as an electron donor and catalyzes the biotransformation of various organic and inorganic peroxides [29]. We noticed that $150 \%$ increase in GPX activity could compensate, at least partially, the strong AMT-induced CAT inactivation, in terms of hydrogen peroxide removal. We also noticed an increase in GR activity in AMT-treated keratinocytes. The activation of GR, the enzyme, which catalyzes NADPHdependent conversion of GSSG to GSH, has an important role in preventing the alteration of the glutathione status after AMT administration. The GST family contains enzymes that are capable of multiple reactions, with a multitude of substrates in order to detoxify endogenous compounds, such as peroxidized lipids; they are also involved in the metabolism of xenobiotics. Our results show that their activity remained unchanged after AMT treatment and therefore suggest that these enzymes are not involved in detoxification following AMT treatment. Previous reports indicated the activation of the enzymes involved in glutathione cycle after AMT treatment in animal model. Thus, a high level of GPX 
activity was noticed in goldfish brain, liver, and kidney after AMT administration [14, 17]. However, in our experiments, this protective response induced by CAT inactivation did not completely prevent the development of oxidative stress in keratinocytes. The level of lipid peroxidation increased by approximately 2 -fold, while the protein oxidation rose by 1.3 -fold. This difference between the magnitude of the changes registered for the two classes of macromolecules likely reflected their different susceptibilities to oxidative damage induced by ROS and possibly the intervention or different defense/reparatory mechanisms that counteract their oxidative changes in response to AMT treatment. Cells use different systems in order to provide antioxidant defense, damage removal, and replacement or repair for peroxidized lipids and oxidatively modified proteins. For example, glutathione peroxidase 4 acts as an efficient defense/reparatory enzyme reducing both soluble fatty acid hydroperoxides and also complex lipid hydroperoxides [30]. Peroxiredoxin 6 has also important roles in both antioxidant defense, based on its ability to reduce peroxidized membrane phospholipids, and reparatory mechanism (phospholipid homeostasis) based on its ability to generate lysophospholipid substrate for the remodeling pathway of phospholipid synthesis [31]. On the other hand, there are only few mechanisms involved in the recovery of the native state for oxidatively modified proteins: (i) intramolecular and intermolecular disulfide cross-links can be reversed to some extent by disulfide reductases; (ii) the enzyme methionine sulfoxide reductase can regenerate Met [32]. Protein carbonylation is considered an irreversible oxidative protein modification [33].

The compensatory response to CAT inhibition we observed in this study suggests that AMT might have potential value in modulating the effect of oxidative stress induced by various environmental factors, such as UVA radiation, when acting on skin cells. To understand the interference of AMT with the effects of UVA exposure in skin cells, we first attempted to evaluate the effect of AMT pretreatment on the viability of UVA-irradiated keratinocytes. Previous studies have shown that UVA exposure of cultured keratinocytes can lead to decrease in cell survival, depending on the irradiation intensity and exposure time $[34,35]$. In the current work, we observed a moderate cytotoxicity after $18.7 \mathrm{~J} / \mathrm{cm}^{2}$ of UVA exposure, measured as a decrease in cell viability of about $25 \%$. In a study conducted by Huang et al. [20], the authors reported a decrease of $\mathrm{HaCaT}$ keratinocytes viability by $38 \%$ after $20 \mathrm{~J} / \mathrm{cm}^{2}$ UVA exposure. AMT treatment also decreased cell viability, but the combined action of the two factors was not cumulative.

Using DOK cells as an in vitro model, our study showed that UVA irradiation decreased the level of the antioxidant defense enzymes. Therefore, the exposure of DOK cells to UVA radiation decreased significantly CAT, GPX, and GR activities, and, to a lesser extent, the GST level. In previous studies, such UVA-induced alterations in antioxidant enzymes have been also reported in cell culture experiments [36-38].

A very low level in CAT activity was recorded in AMTtreated and UVA-exposed DOK cells. Despite this effect, the harmful oxidative changes induced by UVA exposure were partially limited, probably due to the rise of GPX and GR activities, as a consequence of AMT treatment prior irradiation. The increase recorded in antioxidant enzymes activities was not enough to reduce the high level of UVA-induced lipid peroxidation. Thus, the AMT administration before irradiation, apparently cannot limit the undesirable consequences associated with UVA-induced lipid peroxidation.

UVA radiation is known to cause extensive protein modification [39]. Oxidation of protein side chains containing proline, arginine, lysine, and threonine results in the formation of carbonyl groups. In the current work, the quantification of protein profiles obtained suggested a sharp increase in carbonylated proteins after UVA exposure of keratinocytes. The increase in protein carbonylation upon UVA exposure was also reported in human dermis and epidermis [40] and in skin cell culture experiments [41]. Carbonylation of proteins is an irreversible oxidative damage, often leading to the accumulation of structurally and functionally impaired proteins [42]. Whereas moderately carbonylated proteins are degraded by the proteasome system, heavily carbonylated proteins form high-molecular-weight aggregates are resistant to proteasomal degradation and accumulate as damaged, unfolded proteins. Such aggregates seem to be involved in the pathogenesis of various skin diseases [43]. In our study, AMT treatment of DOK cells prior to UVA exposure decreased the UVA-induced protein oxidation. This observed decrease could have resulted from reduced ROS level, as a result of the AMT intensifying antioxidant enzymes activities.

In conclusion, AMT treatment of DOK cells induced a moderate oxidative stress as indicated by an increased level of MDA and carbonylated proteins. Although AMT reduced cellular CAT activity, the level of hydrogen peroxide and the extent of the oxidative damage were lower than expected, likely due to the compensatory activation of other antioxidant enzymes. Our results also showed that AMT treatment of DOK cells prior toUVA exposure limited the UVA-induced oxidative damage of proteins. A protective effect of AMT was previously reported. Thus, AMT effectively attenuated carbon tetrachloride-induced oxidative liver damage [44] and acetaminophen-induced mice hepatotoxicity were reported [45], but in vitro studies were not reported. Further mechanism-based studies are required to explain the interference of AMT with UVA irradiation in keratinocytes cells.

\section{Conflicts of Interest}

The authors declare that they have no conflicts of interest.

\section{Acknowledgments}

The authors thank Dr. Gabriela K. Popescu, University of Buffolo, New York, for the English revision of the manuscript.

\section{References}

[1] C. Battie and M. Verschoore, "Cutaneous solar ultraviolet exposure and clinical aspects of photodamage," Indian Journal 
of Dermatology, Venereology and Leprology, vol. 78, no. 1, pp. 9$14,2012$.

[2] L. Rittié and G. J. Fisher, "Natural and sun-induced aging of human skin," Cold Spring Harbor Perspectives in Medicine, vol. 5, no. 1, 14 pages, 2015.

[3] N. S. Agar, G. M. Halliday, R. S. C. Barnetson, H. N. Ananthaswamy, M. Wheeler, and A. M. Jones, "The basal layer in human squamous tumors harbors more UVA than UVB fingerprint mutations: a role for UVA in human skin carcinogenesis," Proceedings of the National Acadamy of Sciences of the United States of America, vol. 101, no. 14, pp. 4954-4959, 2004.

[4] L. A. Applegate and E. Frenk, "Cellular defense mechanisms of the skin against oxidant stress and in particular UVA radiation," European Journal of Dermatology, vol. 5, no. 2, pp. 97-103, 1995.

[5] C.-H. Huang, H.-J. Li, N.-L. Wu et al., "Photoprotective effects of cycloheterophyllin against UVA-induced damage and oxidative stress in human dermal fibroblasts," PLoS ONE, vol. 11, no. 9, Article ID e0161767, 2016.

[6] P. M. Girard, S. Francesconi, M. Pozzebon et al., "UVAinduced damage to DNA and proteins: direct versus indirect photochemical processes," Journal of Physics: Conference Series, vol. 261, no. 1, Article ID 012002, 10 pages, 2011.

[7] R. Brem, M. Guven, and P. Karran, "Oxidatively-generated damage to DNA and proteins mediated by photosensitized UVA," Free Radical Biology \& Medicine, vol. 107, pp. 101-109, 2016.

[8] F. Afaq and H. Mukhtar, "Effects of solar radiation on cutaneous detoxification pathways," Journal of Photochemistry and Photobiology B: Biology, vol. 63, no. 1-3, pp. 61-69, 2001.

[9] F. Rolfs, M. Huber, F. Gruber et al., "Dual role of the antioxidant enzyme peroxiredoxin 6 in skin carcinogenesis," Cancer Research, vol. 73, no. 11, pp. 3460-3469, 2013.

[10] C. MICHIELS and J. REMACLE, "Use of the inhibition of enzymatic antioxidant systems in order to evaluate their physiological importance," European Journal of Biochemistry, vol. 177, no. 2, pp. 435-441, 1988.

[11] C. Michiels, M. Raes, O. Toussaint, and J. Remacle, "Importance of se-glutathione peroxidase, catalase, and $\mathrm{Cu} / \mathrm{Zn}$-SOD for cell survival against oxidative stress," Free Radical Biology \& Medicine, vol. 17, no. 3, pp. 235-248, 1994.

[12] E. Margoliash, A. Novogrodsky, and A. Schejter, "Irreversible reaction of 3-amino-1:2:4-triazole and related inhibitors with the protein of catalase," Biochemical Journal, vol. 74, pp. 339348,1960 .

[13] R. G. Allen, K. J. Farmer, and R. S. Sohal, "Effect of catalase inactivation on levels of inorganic peroxides, superoxide dismutase, glutathione, oxygen consumption and life span in adult houseflies (Musca domestica).," Biochemical Journal, vol. 216, no. 2, pp. 503-506, 1983.

[14] T. V. Bagnyukova, O. Y. Vasylkiv, K. B. Storey, and V. I. Lushchak, "Catalase inhibition by amino triazole induces oxidative stress in goldfish brain," Brain Research, vol. 1052, no. 2, pp. 180-186, 2005.

[15] S. Douiri, S. Bahdoudi, Y. Hamdi et al., "Involvement of endogenous antioxidant systems in the protective activity of pituitary adenylate cyclase-activating polypeptide against hydrogen peroxide-induced oxidative damages in cultured rat astrocytes," Journal of Neurochemistry, vol. 137, pp. 913-930, 2016.

[16] F. J. Ruiz-Ojeda, C. Gomez-Llorente, C. M. Aguilera, A. Gil, and A. I. Rupérez, "Impact of 3-amino-1,2,4-triazole (3-AT)-derived increase in hydrogen peroxide levels on inflammation and metabolism in human differentiated adipocytes," PLoS ONE, vol. 11, no. 3, Article ID e0152550, 2016.

[17] T. V. Bagnyukova, K. B. Storey, and V. I. Lushchak, "Adaptive response of antioxidant enzymes to catalase inhibition by aminotriazole in goldfish liver and kidney," Comparative Biochemistry and Physiology-B Biochemistry and Molecular Biology, vol. 142, no. 3, pp. 335-341, 2005.

[18] C. Gavrila, I. Gruia, and C. P. Lungu, "Determining the radial distribution of the emission coefficient from a plasma source," Journal of Optoelecronics and Advanced Materials, vol. 8, pp. 835-838, 2009.

[19] E. Borenfreund and J. A. Puerner, "Toxicity determined in vitro by morphological alterations and neutral red absorption," Toxicology Letters, vol. 24, no. 2-3, pp. 119-124, 1985.

[20] C.-C. Huang, J.-Y. Fang, W.-B. Wu, H.-S. Chiang, Y.-J. Wei, and C.-F. Hung, "Protective effects of (-)-epicatechin-3-gallate on UVA-induced damage in HaCaT keratinocytes," Archives of Dermatological Research, vol. 296, no. 10, pp. 473-481, 2005.

[21] M. T. Portolés, M. J. Ainaga, and R. Pagani, “The induction of lipid peroxidation by $\mathrm{E}$. coli lipopolysaccharide on rat hepatocytes as an important factor in the etiology of endotoxic liver damage," BBA-General Subjects, vol. 1158, no. 3, pp. 287292, 1993.

[22] H. Aebi, "Catalase in vitro," in Methods of Enzymatic Analysis, H. U. Bergmayer, Ed., vol. 2, pp. 673-684, F.R.G, Weinheim, Germany, 1984.

[23] E. Beutler, J. C. Kaplan, G. W. Löhr, B. Ramot, and W. $\mathrm{N}$. Valentine, "International committee for standardization in haematology: recommended methods for red-cell enzyme analysis," British Journal of Haematology, vol. 35, no. 2, pp. 331340, 1977.

[24] D. M. Goldberg and R. J. Spooner, "Glutathione reductase," in Methods of Enzymatic Analysis, H. U. Bergmayer, Ed., Dearfield Beach, Verlag Chemie, 1983.

[25] W. H. Habig, M. J. Pabst, and W. B. Jakoby, "Glutathione $S$ transferases. The first enzymatic step in mercapturic acid formation," The Journal of Biological Chemistry, vol. 249, no. 22, pp. 7130-7139, 1974.

[26] M. M. Bradford, "A rapid and sensitive method for the quantitation of microgram quantities of protein utilizing the principle of protein dye binding," Analytical Biochemistry, vol. 72, no. 1-2, pp. 248-254, 1976.

[27] J. J. Thiele, S. N. Hsieh, K. Briviba, and H. Sies, "Protein oxidation in human stratum corneum: susceptibility of keratins to oxidation in vitro and presence of a keratin oxidation gradient in vivo," Journal of Investigative Dermatology, vol. 113, no. 3, pp. 335-339, 1999.

[28] J. J. Yohn, D. A. Norris, D. G. Yrastorza et al., "Disparate antioxidant enzyme activities in cultured human cutaneous fibroblasts, keratinocytes and melanocytes," Journal of Investigative Dermatology, vol. 97, no. 3, pp. 405-409, 1991.

[29] J. R. Arthur, “The glutathione peroxidases," Cellular and Molecular Life Sciences, vol. 57, no. 13-14, pp. 1825-1835, 2000.

[30] R. Brigelius-Flohé and A. Kipp, "Glutathione peroxidases in different stages of carcinogenesis," Biochimica et Biophysica Acta, vol. 1790, no. 11, pp. 1555-1568, 2009.

[31] A. B. Fisher, "Peroxiredoxin 6: A bifunctional enzyme with glutathione peroxidase and phospholipase a2 activities," Antioxidants \& Redox Signaling, vol. 15, no. 3, pp. 831-844, 2011. 
[32] K. J. Davies, "Oxidative stress, antioxidant defenses, and damage removal, repair, and replacement systems," IUBMB Life, vol. 50, no. 4-5, pp. 279-289, 2000.

[33] M. Fedorova, R. C. Bollineni, and R. Hoffmann, "Protein carbonylation as a major hallmark of oxidative damage: update of analytical strategies," Mass Spectrometry Reviews, vol. 33, no. 2, pp. 79-97, 2014.

[34] T. T. Huynh, K. S. Chan, and T. J. Piva, "Effect of ultraviolet radiation on the expression of pp38MAPK and furin in human keratinocyte-derived cell lines," Photodermatology, Photoimmunology \& Photomedicine, vol. 25, no. 1, pp. 20-29, 2009.

[35] I. Izykowska, M. Cegielski, E. Gebarowska et al., "Effect of melatonin on human keratinocytes and fibroblasts subjected to UVA and UVB radiation in vitro," In Vivo, vol. 23, no. 5, pp. 739-745, 2009.

[36] A. Moysan, P. Clément-Lacroix, L. Michel, L. Dubertret, and P. Morlière, "Effects of ultraviolet A and antioxidant defense in cultured fibroblasts and keratinocytes," Photodermatology, Photoimmunology Photomedicine, vol. 11, pp. 192-197, 1996.

[37] J. D. Hoerter, C. S. Ward, K. D. Bale et al., "Effect of UVA fluence rate on indicators of oxidative stress in human dermal fibroblasts," International Journal of Biological Sciences, vol. 4, no. 2, pp. 63-70, 2008.

[38] A. Gegotek, M. Biernacki, E. Ambrozewicz, A. Surazyński, A. Wroński, and E. Skrzydlewska, "The cross-talk between electrophiles, antioxidant defence and the endocannabinoid system in fibroblasts and keratinocytes after UVA and UVB irradiation," Journal of Dermatological Science, vol. 81, no. 2, pp. 107-117, 2016.

[39] D. I. Pattison, A. S. Rahmanto, and M. J. Davies, "Photooxidation of proteins," Photochemical \& Photobiological Sciences, vol. 11, no. 1, pp. 38-53, 2012.

[40] C. S. Sander, H. Chang, S. Salzmann et al., "Photoaging is associated with protein oxidation in human skin in vivo," Journal of Investigative Dermatology, vol. 118, no. 4, pp. 618-625, 2002.

[41] G. F. Vile and R. M. Tyrrell, "Uva radiation-induced oxidative damage to lipids and proteins in vitro and in human skin fibroblasts is dependent on iron and singlet oxygen," Free Radical Biology \& Medicine, vol. 18, no. 4, pp. 721-730, 1995.

[42] N. Tanaka, S. Tajima, A. Ishibashi, K. Uchida, and T. Shigematsu, "Immunohistochemical detection of lipid peroxidation products, protein-bound acrolein and 4-hydroxynonenal protein adducts, in actinic elastosis of photodamaged skin," Archives of Dermatological Research, vol. 293, no. 7, pp. 363-367, 2001.

[43] I. Dalle-Donne, G. Aldini, M. Carini, R. Colombo, R. Rossi, and A. Milzani, "Protein carbonylation, cellular dysfunction, and disease progression," Journal of Cellular and Molecular Medicine, vol. 10, no. 2, pp. 389-406, 2006.

[44] X. Deng, K. Wu, J. Wan et al., "Aminotriazole attenuated carbon tetrachloride-induced oxidative liver injury in mice," Food and Chemical Toxicology, vol. 50, no. 9, pp. 3073-3078, 2012.

[45] Y. Jing, K. Wu, J. Liu et al., "Aminotriazole alleviates acetaminophen poisoning via downregulating P450 2E1 and suppressing inflammation," PLoS ONE, vol. 10, no. 4, Article ID e0122781, 2015. 

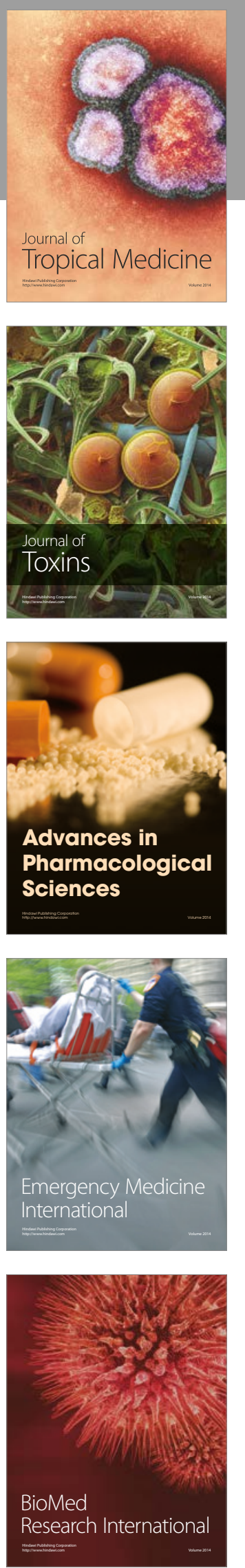
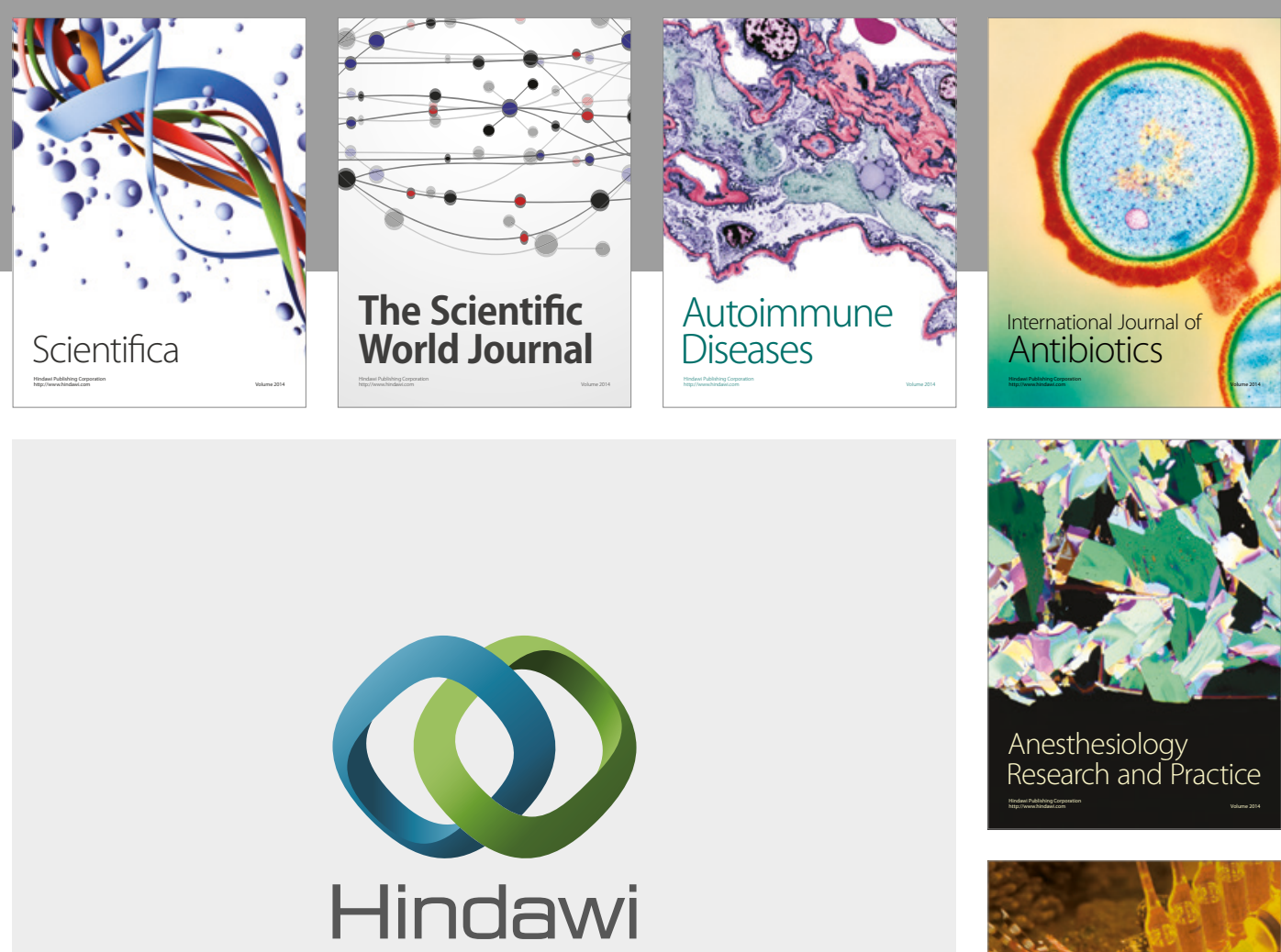

Submit your manuscripts at

https://www.hindawi.com
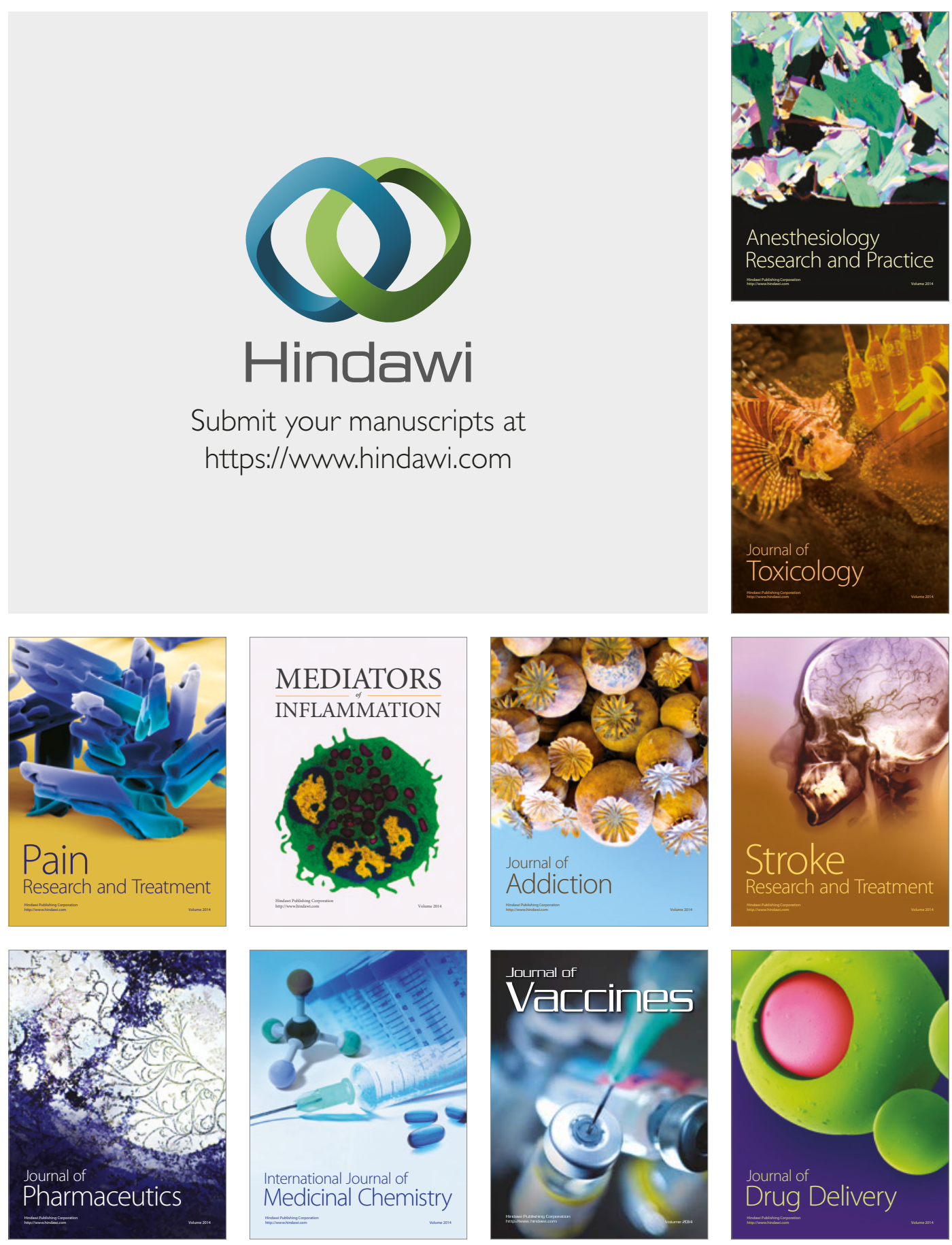